\title{
Changes in lung function after working with the shotcrete lining method under compressed air conditions
}

\author{
R KESSEL, M REDL, R MAUERMAYER, G J PRAML \\ From the Institut und Poliklinik für Arbeitsmedizin der Universität München, D-8000 München 2, Federal \\ Republic of Germany
}

ABSTRACT Shotcrete techniques under compressed air are increasingly applied in the construction of tunnels. Up to now little is known about the influence of shotcrete dusts on the function of the lung. $i$ The lung function of 30 miners working with shotcrete under compressed air (before and after one $\vec{N}$ shift) was measured. They carried personal air samplers to assess the total dust exposure. Long term ${ }^{\infty}$

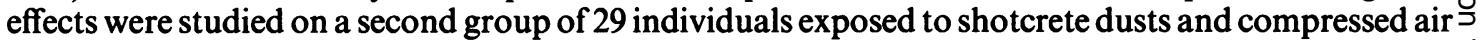
for two years. A significant increase of airway resistance and a significant decrease of some flow- $\vec{T}$ volume parameters were found after one workshift. These changes partially correlate close to the dust $\frac{\mathbb{O}}{0}$ exposure. After two years exposure a significant decrease of mean expiratory flow (MEF) $)_{50}$ and $\frac{2}{0}$ $\mathrm{MEF}_{25}$ was found. These results point to damage in the small airways and emphasise the major role of the lung function test-including the flow-volume manoeuvre for the medical examination of the $\vec{\bullet}$ workers. Additionally, they should carry filter masks.

Tunnels for modern transport systems are increasingly being constructed using shotcrete techniques under compressed air conditions.

The shotcrete method, often referred to as the "new Austrian tunneling method," is a technique of constructing tunnels in soft subsoil with simultaneous temporary protection of the vault (fig 1). Firstly, the advanced upper part of the tunnel cross section is excavated, steel reinforcement profiles are mounted, and the tunnel is secured by shooting a mixture of cement, sand, binding accelerator, and water under high pressure ( $3 \ldots 5$ bar) against the surface (fig 2 ). The same procedure for the lower part completes the final cross section. To remove ground water, compressed air may be used as a construction aid. Reduced ground settlement and minor impairment of residents in the neighbourhood are some of the advantages of this method (H Diselmeiertat Congress on Tunneling, Dusseldorf, 1981).

In the light of current public uncertainty about potential health risks this construction method deserves particular attention. At present little is known about the influence on lung function of shotcrete dusts moving in compressed air.

Our investigation was intended to show whether, and if so in what manner, a short term, single shift

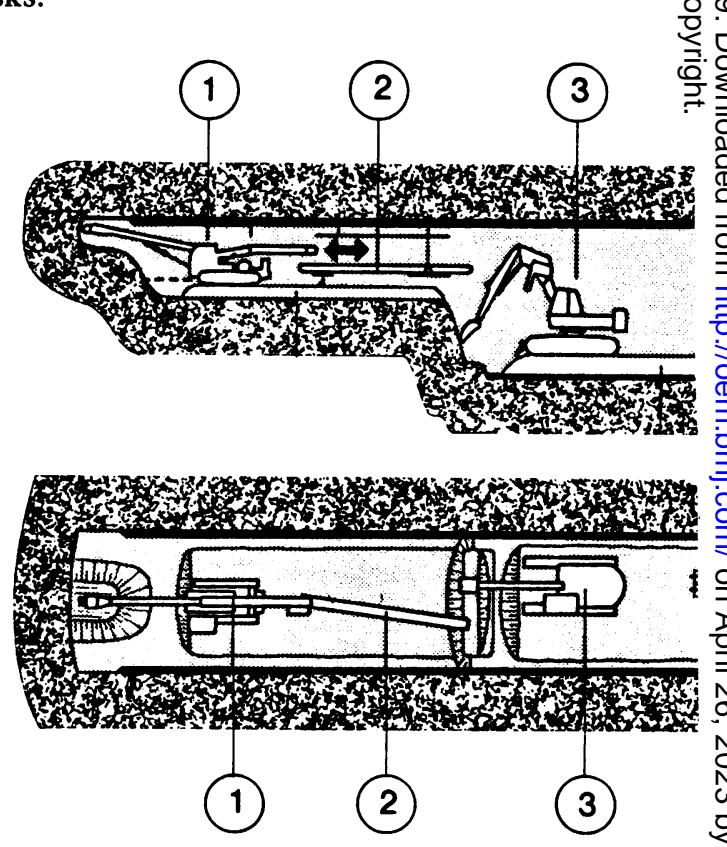

Fig 1 Schematic of tunnel construction with shotcrete lining method. (1) boom cutter loader, (2) conveyor, (3) excavator. Shotcrete nozzle guider ("gunner") works in foremost section of heading, mixer operator works back in tunnel. 


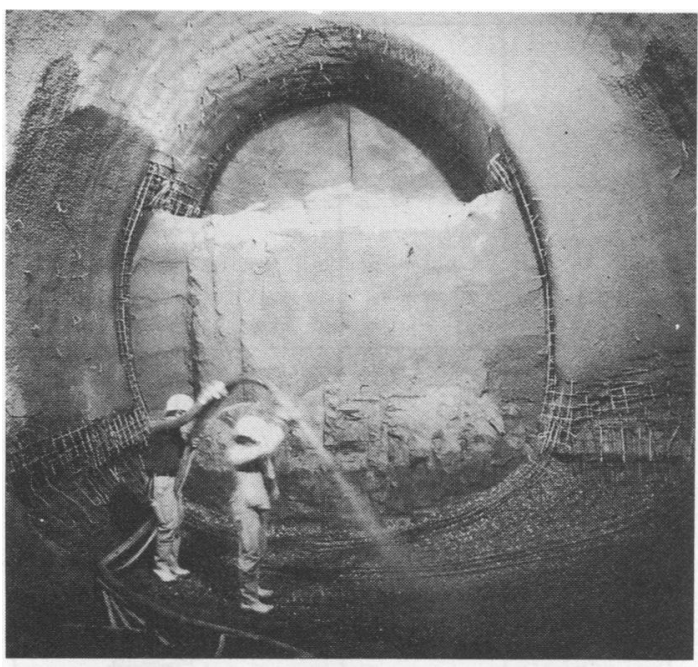

Fig 2 Tunnelling with shotcrete support: application of shotcrete.

exposure influences lung function and whether certain groups of workers have an increased health risk. Furthermore, we wished to look for detectable changes in the lung function of workers exposed over longer periods.

\section{Subjects and methods}

A total of 30 underground workers (mean age 32) was examined before and after a shift working with shotcrete under compressed (on average about 1 bar excess pressure) air. In addition, 29 underground workers permanently exposed to compressed air (mean age 31 ) were examined before and after a period of about two years (table 1).

The afternoon shift (1400-2200) was chosen for the examination of the first group; according to Ulmer, no substantial intra-individual changes in lung function are to be expected during this period of the day. ${ }^{1}$ The following measurements were taken both immediately before locking in and after locking out: inspiratory and forced expiratory vital capacity, forced expiratory volume after one second (FEV 1 ) (Tiffeneau test), and airway resistance (oscillatory method). The flowvolume curve was stored on magnetic tape, ${ }^{2}$ permitting subsequent computerised evaluation of the peak expiratory flow (PEF), the flow related to particular levels of the FVC (maximum expiratory flows when $75 \%, 50 \%$, and $25 \%$ of the FVC remains to be exhaled), and the area enclosed by the flow-volume curve (fig 3). All workers carried a personal air sampler calibrated in compressed air to determine individual dust exposure. The control group was composed of 21 individuals with a mean age of 28 who had never been exposed to dust or to compressed air.

Long term effects were studied by comparing initial lung function data with those after an exposure of about two years. Twenty one non-exposed individuals, mostly non-workers of about the same age, served as a control group.

\section{Results}

The total dust concentration measured by the personal air sampler ranged from 3.2 to $62.1 \mathrm{mg} / \mathrm{m}^{3}$ depending on the particular tasks of the individual worker (table 2). The highest dust load (with an average $26 \mathrm{mg} / \mathrm{m}^{3}$ ) was found among those who guided the shotcrete nozzle, followed by the dumper drivers with $10 \mathrm{mg} / \mathrm{m}^{3}$ and the concrete mixer operators with $7 \mathrm{mg} / \mathrm{m}^{3}$. Workers with more general tasks in the entire tunnel region and the locomotive drivers had the lowest exposure with an average of $3.4 \mathrm{mg} / \mathrm{m}^{3}$.

A full shift exposure to shotcrete under compressed air results in:

a significant increase of the airway resistance by $10 \%$;

a significant decrease of the forced vital capacity by $3 \%$;

a corresponding decrease in the FEV by $4 \%$ (fig 4).

The maximum expiratory flow (PEF) diminishes by $6 \%$ and the maximum expiratory flow by $8 \%$ when $75 \%$ of the FVC remains to be exhaled $\left(\mathrm{MEF}_{75}\right)$ thus reducing the area enclosed by the flow-volume curve by $8.5 \%$ (fig 5 , left part).

It can be shown that the total dust concentration during a working shift correlates with the lung function data. Increasing dust exposure corresponds to a significant decrease of the $\mathrm{FEV}_{1}$ (fig 6), the peak expiratory flow (PEF), and the maximum expiratory flow when $75 \%$ of the FVC remains to be exhaled $\left(\mathrm{MEF}_{75}\right)$. Consequently the area enclosed by the flowvolume curve decreases significantly with increasing total dust concentration. Non-smokers show these

Table 1 Subjects examined

\begin{tabular}{|c|c|c|c|c|}
\hline \multirow[b]{2}{*}{ Subjects } & \multicolumn{2}{|c|}{$\begin{array}{l}\text { Before and after one shift } \\
(1400-2200)\end{array}$} & \multirow{2}{*}{$\begin{array}{l}\text { Before and after } \\
22 \pm 4 \text { months, } \\
\text { Exposed }\end{array}$} & \multirow{2}{*}{$\frac{26 \pm 5 \text { months }}{\text { Controls }}$} \\
\hline & Exposed & Controls & & \\
\hline $\begin{array}{l}\text { No } \\
\text { Age (y) } \\
\text { Height (cm) } \\
\text { Weight (kg) } \\
\text { Smokers }\end{array}$ & $\begin{array}{l}30 \\
32 \pm 8 \\
177 \pm 6 \\
78 \pm 12 \\
14\end{array}$ & $\begin{array}{r}21 \\
29 \pm 6 \\
180 \pm 6 \\
76 \pm 9 \\
10\end{array}$ & $\begin{array}{c}29 \\
31 \pm 8 \\
177 \pm 6 \\
76 \pm 10 \\
18\end{array}$ & $\begin{aligned} 21 & \\
36 & \pm 6 \\
178 & \pm 6 \\
78 & \pm 10 \\
7 & \end{aligned}$ \\
\hline
\end{tabular}




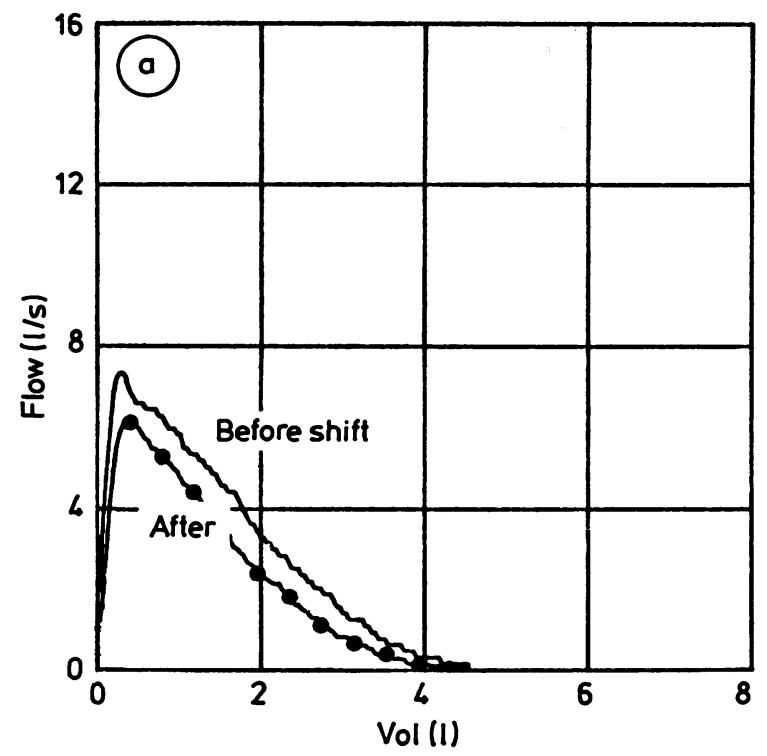

Fig 3 Original flow volume curves; changes in dependence on total dust exposure. (a) Man aged $48,169 \mathrm{~cm}, 65 \mathrm{~kg}$, total dust exposure $12 \mathrm{mg} / \mathrm{m}^{3}$. (b) Man aged $35,184 \mathrm{~cm}, 86 \mathrm{~kg}$, total dust exposure $1 \mathrm{mg} / \mathrm{m}^{3}$.

effects considerably more than smokers (fig 7).

An exposure of about two years does not lead to a substantial difference between case and control group so far as VC and FEV 1 are concerned. Nevertheless, a significant decrease of the MEF when $50 \%$ and $25 \%$ of the FVC remains to be exhaled is observed (fig 5, right part). Smoking habits have no influence on this effect.

\section{Discussion}

The shotcrete construction method under compressed air has already become standard. It has been applied since 1981, for example, in constructing tunnels for Munich's subway system. The obvious technical advantages and safety and cost considerations give this method a growing international importance. Little is known, however, about its potential risks to health. Several occupations related to this particular construction method cause highly significant cardiocirculatory strains, as we know from our own investigations. ${ }^{34}$ Moreover, shotcrete gun operators are subject to the highest total dust exposure, averaging

Table 2 Shotcrete lining method (compressed air)

Workplace and total dust concentrations (measured by personal air sampler)

\section{Shotcrete work}

Dredger

Mixer

Everywhere in tunnel

Locomotive driver
$25.6 \pm 22.8 \mathrm{mg} / \mathrm{m}^{3}$

$10.2 \pm 2.1 \mathrm{mg} / \mathrm{m}^{3}$

$6.5 \pm 3.7 \mathrm{mg} / \mathrm{m}^{3}$

$3.4 \pm 0.8 \mathrm{mg} / \mathrm{m}^{3}$
$7.4 \pm 3.4 \mathrm{mg} / \mathrm{m}^{3}$
$26 \mathrm{mg} / \mathrm{m}^{3}$. In conjunction with an augmented minute ventilation due to major cardiocirculatory strain, an increased intake of potentially harmful particles mgse be assumed, especially for the gun operators. This hypothesis is supported by our lung function d\$요 obtained before and after a working shift; significam

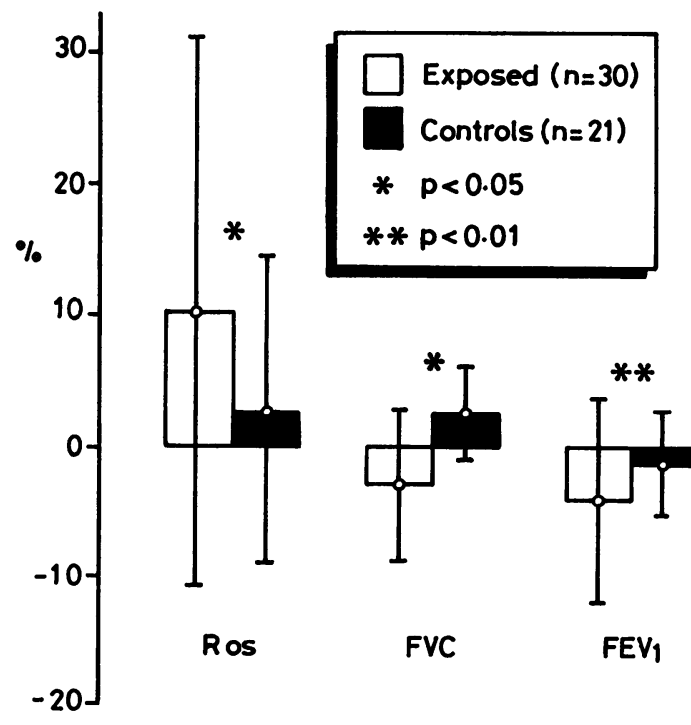

Fig 4 Relative changes in airway resistance (Ros, forced vital capacity $(F V C)$, and Tiffeneau test $\left(F E V_{1}\right)$ from 1400 to 2200 

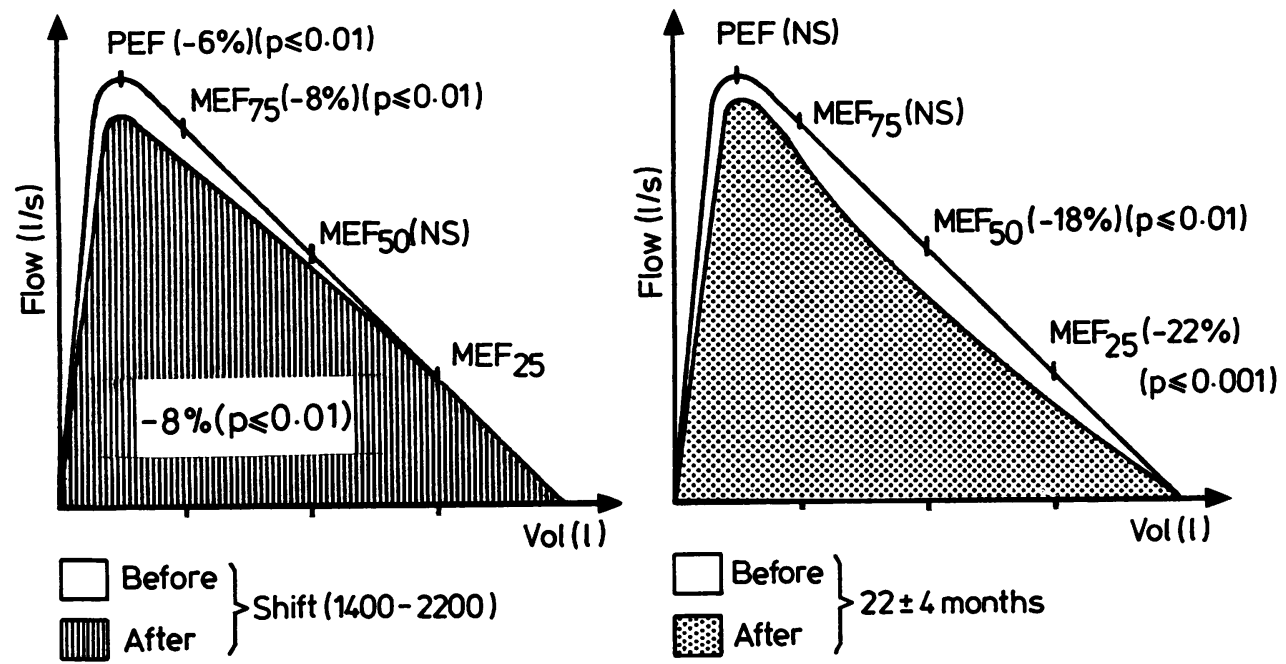

Fig 5 Changes in flow-volume curve after one shift (left part) and after nearly two years (right part).

changes were observed, mainly concerning the flowvolume curve. We find a good correlation with total dust exposure: the higher the dust concentration, the worse the lung function measurements.

Our results from a short term single shift exposure and from a group with about two years exposure to shotcrete under compressed air point to a particular risk concerning the respiratory system. Up to now nothing can be said about the specific shotcrete components responsible for these effects. The binding

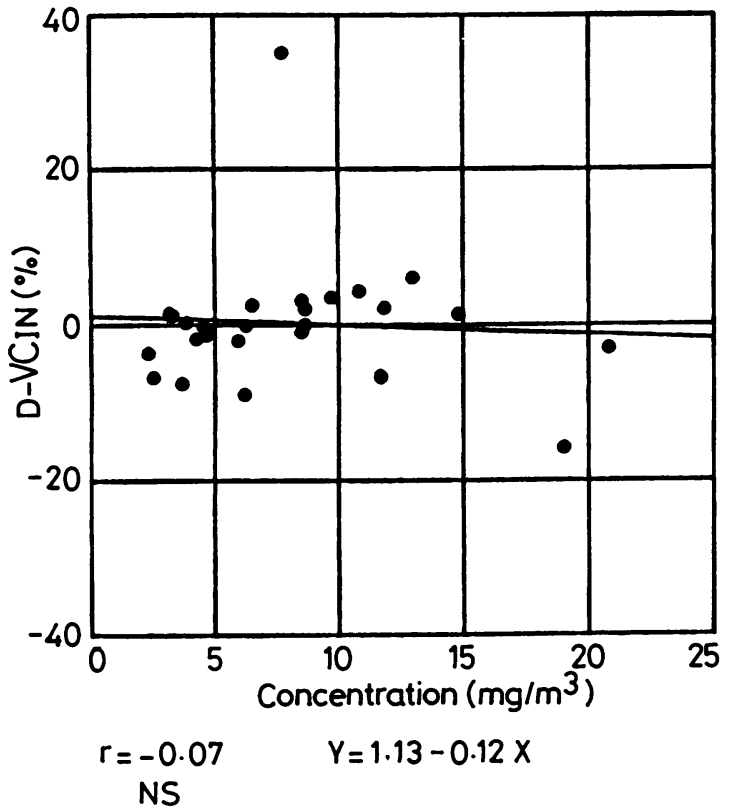

accelerator may well contain quartz; in any case it shows a strong alkaline reaction and may provoke poorly healing skin ulcers. Several publications have shown that cement dusts even without additives can aggravate lung function, but the results are ambiguous at best. A study on chronic bronchitis by the Deutsche Forschungsgemeinschaft emphasised age and smoking habits rather than cement dusts as the significant factors. ${ }^{5}$

Kalacic and Saric et al, on the other hand, found

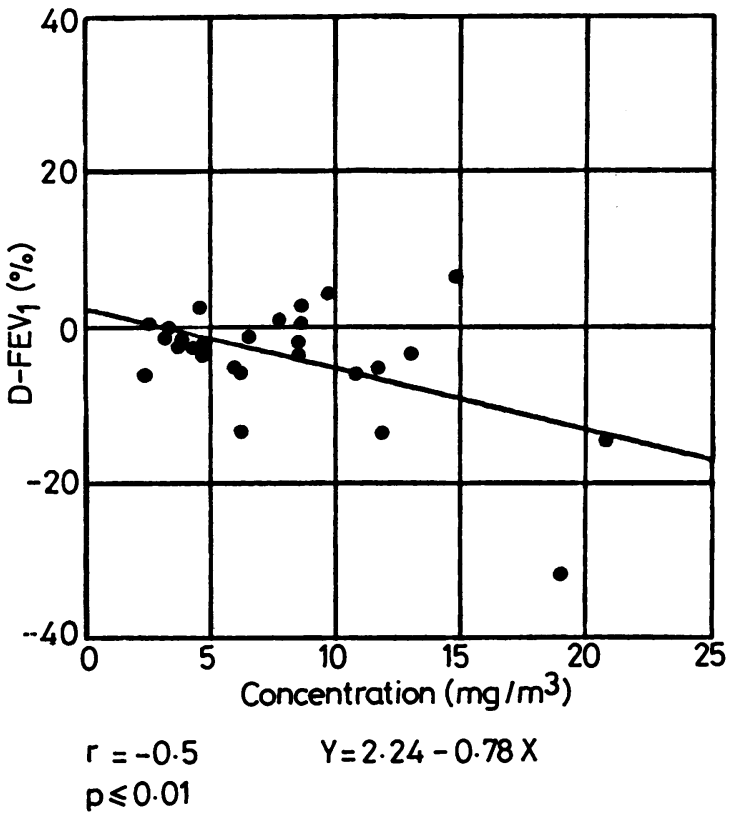

Fig 6 Changes in lung function; in opposition to behaviour of vital capacity FEV decreases more in dependence on a higher total dust exposure. (Because of some higher dust concentrations (up to $62 \cdot 1 \mathrm{mg} / \mathrm{m}^{3}$ in the whole group and $53 \cdot 3 \mathrm{mg} / \mathrm{m}^{3}$ in the group of non-smokers) the missing dots cannot be drawn into this diagram which has a range from $0.0 \mathrm{to} 25 \mathrm{mg} / \mathrm{m}^{3}$.) 


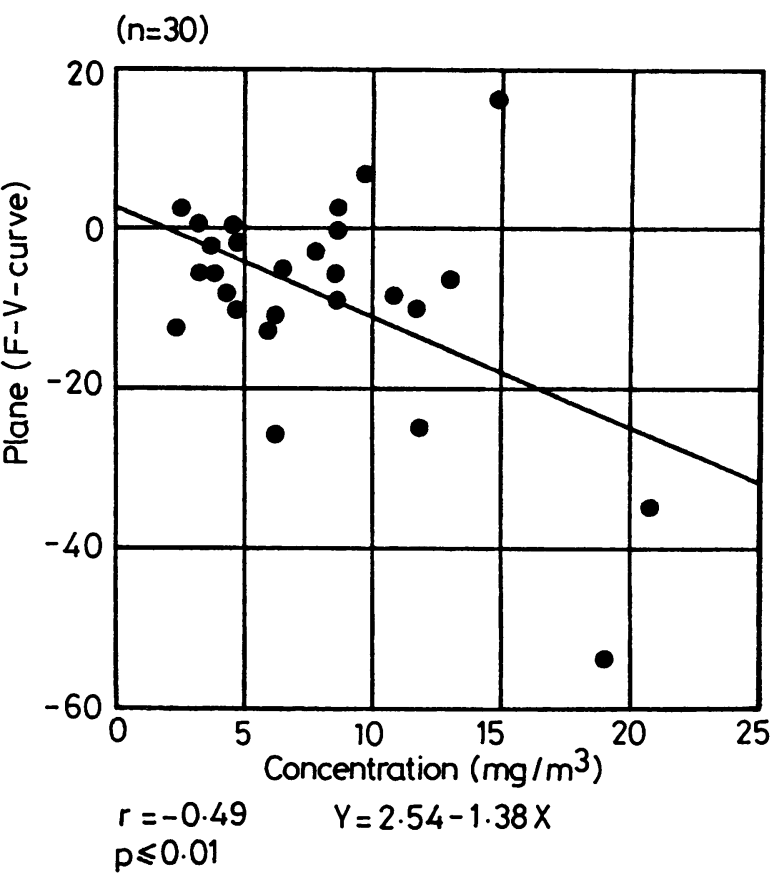

Non-smokers $(n=14)$

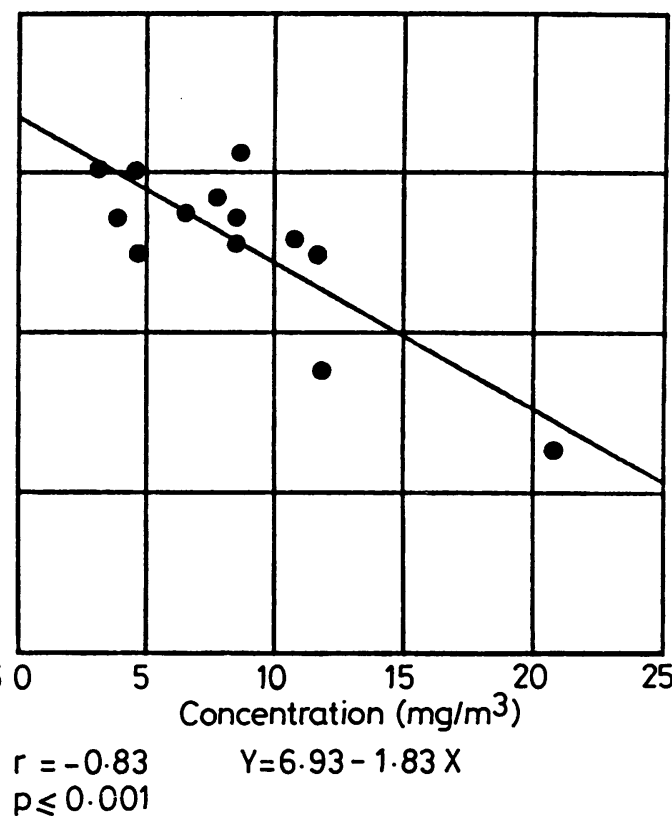

Fig 7 Area below flow-volume curves decreases significantly in dependence on higher total dust exposure.

significant differences between the lung function data of workers exposed to cement dusts and those of a control group: decreases in the FVC, FEV 1 and the $\mathrm{MEF}_{75,50 \text {, and 25. }}{ }^{67}$ These findings agree with the present results.

It would be of interest to know more about the size distribution and deposition characteristics of dusts in an environment with compressed air. Does the risk depend mainly on the respirable dust fraction containing quartz particles that will be deposited in the alveoli and finally provoke a fibrosis? Or does it depend on the total dust in the bronchi, strongly alkaline and hygroscopic? The deposition of inhaled dust in the bronchi and alveoli is supposed to be diminished in a compressed air environment, as Stahlhofen could demonstrate theoretically (unpublished data) and Gussman and Beeckmans could confirm. ${ }^{8}$ Our results, showing increasing airway resistance and decreasing peak flow as well as $\mathrm{MEF}_{75}$ over a single work shift, are in fact compatible with this theory.

Our results illustrate the importance of lung function tests for the medical examination of workers exposed to shotcrete. Early changes, however, cannot be seen when the test is restricted to VC and FEV . We recommend that the flow-volume is also studied in order to judge the maximum expiratory flows at different levels of the remaining volume. And as a fina word of advice: workers should wear filter masks.

This work was supported by a grant from BMFT (FK OIVD4927).

\section{References}

1 Ulmer WT. Pathophysiologische Grundlagen obstruktiver Atemwegserkrankungen. Dtsch Med Wochenschr 1975;100:1575-9.

2 Praml G, Mauermayer R. Flow-Volume-Kurve: Speicherung einzelner Atemzüge auf Magnetband. Prax Klin Pneumol 1983;37:232-5.

3 Holbach M, Kessel R. Beanspruchungsformen spezifischer Tatigkeiten beim Stollenvortrieb in Spritzbetonbauweise unter Druckluft Stuttgart. Gentner Verlag, 1985:61-5.

4 Kessel R, Praml G, Schaefers M. Die kardiozirkulatorische Beanspruchung durch den Untertagevortrieb in Druckluft. Arbeitsmed-Sozialmed-Präventivmed 1982;17:282-5.

5 Valentin $\mathrm{H}$, et al. (Bearb.)/Deutsche Forschungsgemeinschaft: Forschungsberichte Chronische Bronchitis Teil 1 (1975) und 2 (1981) Boldt Druck, Boppard.

6 Kalacic I. Chronic nonspecific lung disease in cement workers. Arch Occup Environ Health 1973;26:78-83.

7 Saric M, Kalacic I, Holetic A. Follow-up of ventilatory lung $\mathrm{N}$ function in a group of cement workers. Br J Ind Med 1976;33:18-24.

8 Gussman RA, Beeckmans JM. Theoretical considerations for $\underline{C}$ pulmonary disposition in high pressure environments: a model. $\mathscr{D}$ In: Walton WH, ed. Inhaled particles III. Old Woking: Unwin Brothers Ltd, 1970: 33-40. N

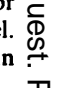
을. N

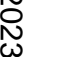

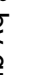

